\title{
Micropolítica e o Exercício da Pesquisa- intervenção: Referenciais e Dispositivos em Análise
}

Micro-politics and the practice of intervention-research: References and devices in analysis

Katia Faria de Aguiar

Universidade Federal

Fluminense

Marisa Lopes da Rocha Universidade do Estado do

Rio de Janeiro

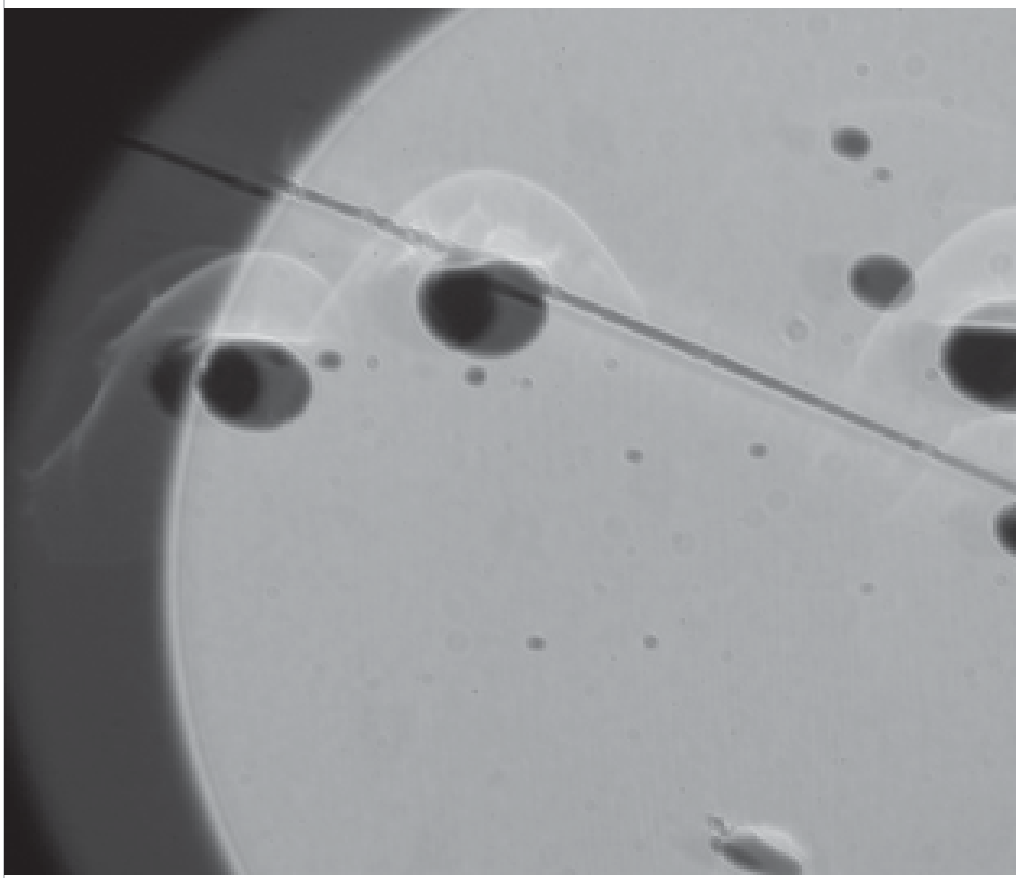




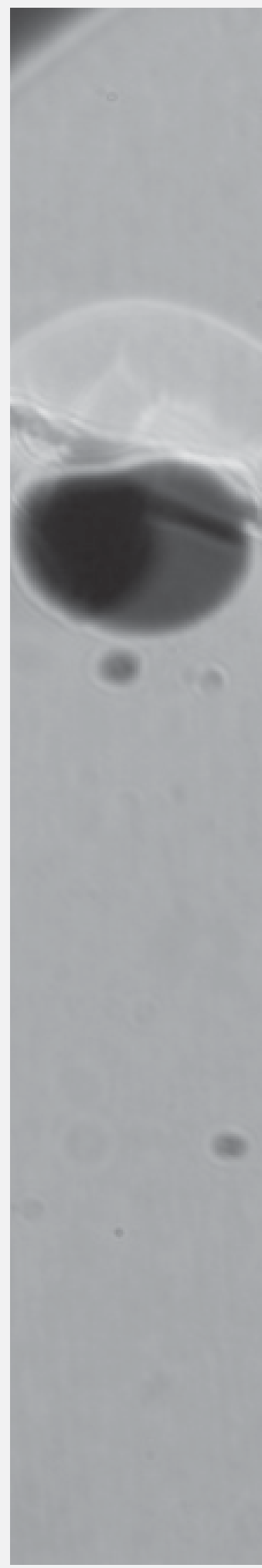

Resumo: Este trabalho tem como objetivo o aprofundamento da discussão dos referenciais da pesquisa-intervenção como uma investigação participativa que busca a interferência coletiva na produção de micropolíticas de transformação social. Inicialmente, destacamos algumas polêmicas que envolvem tanto os referenciais cientificistas clássicos quanto os denominados críticos, que emergem a partir de 1970 para fundamentar pesquisas comunitárias e educacionais nas ciências humanas e sociais. Pretendemos apontar seus limites na análise das instituições e na contribuição para mudanças das práticas. A seguir, procedemos ao exame dos conceitos de real e de pensamento, dando suporte à proposta da pesquisa-intervenção. Tais conceitos serão discutidos a partir da perspectiva genealógica, para colocar em discussão o movimento como diferença. Tratamos também das referências disponibilizadas pelo institucionalismo, vinculadas à socioanálise e à esquizoanálise, que evidenciam as ferramentas de pesquisa e de intervenção na experiência social. Nas considerações finais, destacamos as contribuições das reflexões construídas no texto, que abre caminho para novas interrogações na invenção de outras análises, movimentos e demandas. Palavras-chave: pesquisa-intervenção, pesquisa participante, micropolítica e formação.

Abstract: This paper aims to discuss intervention-research as a participatory investigation that tries to set up collective interference in the production of micro-politics for social changing. Firstly we enlighten some of the polemics that envolve not only the classical scientificist paradigms, but also the critical ones that emerge from 1970 on in order to support community and educational research in social and human sciences. We intend to show their insufficiencies in the analysis of institutions and in the contribution for changes in the practices. Afterwards we shall review the concepts or real and thinking, giving support to the proposal of intervention-research. These concepts wil be discussed on the basis of a genealogical point of view so as to allow us to apprehend movement as difference. We shall also consider the references brought to light by institucionalism, which are put forward by socioanalysis and schizoanalysis, expliciting the tools of research and intervention in social experience. At last, we shall emphasize the contributions of the reflections built in the text, that enable new questions in the invention of other analysis, movements and demands.

Key words: intervention-research, participatory research, micro-politics and formation. 
Este trabalho tem como objetivo o aprofundamento da discussão dos referenciais da pesquisa-intervenção, como investigação participativa que busca a interferência coletiva na produção de micropolíticas de transformação social. Para isso, em Retomando os desafios das pesquisas participativas, destacamos algumas polêmicas que envolvem tanto os referenciais cientificistas clássicos quanto os denominados críticos, que emergem, a partir de 1970, para fundamentar pesquisas comunitárias e educacionais nas ciências humanas e sociais. Pretendemos apontar seus limites na análise das instituições e na contribuição para mudanças das práticas. Em Os referenciais sociopolíticos da pesquisaintervenção, procedemos ao exame dos conceitos de real e de pensamento, dando suporte à proposta da pesquisa-intervenção. Tais conceitos serão discutidos a partir da perspectiva genealógica para colocar em discussão o movimento como diferença. A seguir, em Novas ferramentas interventivas: experiências de transformação em território psi, tratamos das referências disponibilizadas pelo institucionalismo, vinculadas à socioanálise e à esquizoanálise, que evidenciam as ferramentas de pesquisa e de intervenção na experiência social. Nas considerações finais, Práticas de pesquisa: outros suportes, novos desafios, destacamos as contribuições das reflexões construídas no texto, que abrem caminho para novas interrogações na invenção de outras análises, movimentos e demandas.

\section{Retomando os desafios das pesquisas participativas}

Para aprofundar os referenciais da pesquisaintervenção e contribuir para as discussões atuais nesse campo, partimos da afirmação de que o sujeito do conhecimento se produz em meio às práticas sociohistóricas, ou seja, o conhecimento enquanto produção e o sujeito inscrito nesse processo se fazem em condições determinadas, o que torna imprópria qualquer alusão acerca de uma possível neutralidade que nortearia as práticas de pesquisa. Essa assertiva, que hoje nos parece uma óbvia constatação, encontra forte ancoragem na conjuntura dos anos 70 do século passado. Se a convocação de participação da população em ações locais de diagnóstico sobre as condições de vida já podia ser observada desde a década de 40 , será entre os anos 70 e 80 que a perspectiva participante nas pesquisas ganham sentido de ruptura com o status quo. É certo que as disputas no campo das ciências já traziam abalos e questionamentos aos paradigmas até então consolidados, mas sem visibilidade fora da comunidade científica. Tais abalos só encontrarão ressonâncias na nova qualidade de insurgência observada a partir dos anos 60, com os movimentos da contra- cultura e de resistência popular. Esse foi um momento histórico cujo contexto está implicado em forte repressão política, com a saída de militantes e intelectuais do País, com a desestabilização e conseqüente enfraquecimento dos movimentos populares. Mas a luta pela democracia se manteve, quer pelo trabalho clandestino de diferentes setores marginalizados, quer pela colaboração de intelectuais e de setores da igreja vinculados ao movimento da Teologia da Libertação e das Comunidades Eclesiais de Base (Rizzini, Castro; Sartor, 1999). As referências para as ações politizadas se sustentavam nos marxismos, na proposta de educação popular de Paulo Freire e, no campo psi, as experiências grupais apresentam novas formas de ação coletiva comprometidas com a interferência nos rumos da transformação social. Nelas se fizeram presentes muitos psicólogos, descando-se aqueles que atuavam no campo da denominada psicologia comunitária e/ou em processos educativos junto a grupos e organizações de iniciativa popular.

Se novos personagens entram em cena no campo de disputas por um projeto de sociedade, como afirma Sader (1988), e estes passam a se constituir em sujeitos políticos, as 
questões sociais tinham que ser polemizadas com esses novos coletivos no cotidiano. A contextualização das práticas passa a ser condição de realização das pesquisas participativas críticas, uma vez que o cotidiano, na sua dimensão de movimento, traz a análise das forças presentes nas questões e nas ações empreendidas, o que evidencia a complexidade dos processos de trabalho e de produção de conhecimento.

Os referenciais teórico-metodológicos do modelo clássico de pesquisa científica estão em xeque frente à complexidade dos modos de existência e de organização social. Isso é relevante, principalmente junto aos setores populares, para quem as ações comunitárias e educacionais críticas se dirigiam. Novas vozes faziam coro por qualidade de vida para todos, buscavam intervenções na ordem vigente e evidenciavam a diversidade das formas de inserção da vida social, com destaque para os movimentos negro, feminista, homossexuais, por habitação... Tornava-se cada vez mais difícil compreender os modos de funcionamento social tendo como pressuposto apenas o corte de classe. $\mathrm{O}$ que se delineava como desafio na investigação do cotidiano estava implicado na análise de uma realidade em construção, móvel, sem fatos bem delimitados em um princípio, meio e fim, mas com múltiplas entradas possíveis para a interrogação das práticas.

Era fundamental a produção de outros suportes para as investigações a partir do questionamento das bases das pesquisas tradicionais que se apoiavam na dicotomização entre ciência e política. Para desenvolver uma metodologia participativa, tornou-se necessária a mudança na postura do pesquisador e dos pesquisados, uma vez que todos passam a ser co-autores do processo de diagnóstico da situação-problema e da construção de caminhos para o enfrentamento e solução das questões. É um processo contínuo que acontece no curso da vida diária, transforma os sujeitos e demanda desdobramentos de práticas e relações entre os participantes (Oliveira e Oliveira, 1983). “O pesquisador, nessa nova visão, apresenta-se como um intelectual orgânico às causas populares, e a Pesquisa-Ação se traduz em um método potencializador na organização de espaços de participação coletiva. Política e educação, política e organização de comunidades constituem-se em relações possíveis para transformar a realidade”(Rocha, \& Aguiar, 2003:p.66).

No entanto, é importante colocar em discussão os limites dos referenciais que se configuraram como ações politizadas, uma vez que os tensionamentos vinculados aos novos movimentos sociais se inscreviam em uma realidade complexa e multireferencializada que o marxismo clássico reduzia ao contexto das lutas de classe. Além do reducionismo social, a preocupação com a denominada dimensão política, grande parte das vezes, separou forma de conteúdo, mantendo a dicotomização entre metodologia (forma de ação) e teorias críticas a dominar (conteúdo desalienante), postura que, mesmo quando se tenta integrar, deixa ainda a concepção do político fora de questão. Isso significa que avançar no trabalho é, ao mesmo tempo, ensinar-aprender o conteúdo para qualificar as pessoas da comunidade e os serviços específicos a elas prestados, através de técnicas de mudança que visam à conscientização e à conquista da autonomia. Aqui, a liberdade é a superação das desigualdades de classe e, para isso, é necessária a utilização de metodologias que possam desvendar as ideologias que encobrem a realidade.

De todo modo, o problema implicado nesse referencial crítico de pesquisa está na perspectiva de transformação marcada pela centralidade da consciência. Embora muitas propostas tenham inspiração nos marxismos, elas parecem reeditar o equívoco que o próprio Marx já havia denunciado em seu tempo: a 
O mito racionalista se atualiza tanto

conscientização quanto no consenso regulador de múltiplas

racionalidades, como estratégias dialógicas (políticopedagógicas) que, em lugar da emancipação, ratificamo controle e a tutela. cisão entre o sujeito da experiência (da luta) e o sujeito do conhecimento, acalentando a expectativa de que, a partir da aquisição de conhecimentos, a verdade possa iluminar a experiência de luta contra a exploração e ajude a superar os obstáculos, habitantes da ignorância ideológica, que se interpõem à transformação. Em nosso entender, um equívoco das chamadas metodologias participativas críticas reside no fato de tomarem como ponto de partida algo que elas mesmas tencionam construir: a democracia. Esta deixa de ser um exercício micropolítico que pensa as formas de poder entre parceiros na própria pesquisa para se constituir em uma cartilha $a$ priori que é preciso dominar. Assegura a palavra em um nível do trabalho coletivo, mas não garante as condições de interferência coletiva. Esquecem-se da imperiosa desigualdade dos discursos, impregnados pelas posições e injunções do poder, nas circunstâncias. Não estamos negando a validade das propostas de participação, no sentido da criação de espaços e de condições ao exercício de um pensamento combativo; o que temos como questão são as próprias condições nas quais se realizam os combates. O que para nós está em jogo são as ilusões e os mitos que nesses exercícios costumam ser perpetuados, reeditando um 'otimismo socrático-platônico' que credita ao conhecimento o caminho para a transformação (armadilhas que concentram a solução pelo acesso ao conhecimento) e a essa emancipação intelectual, a garantia da autonomia. O mito racionalista se atualiza tanto na conscientização quanto no consenso regulador de múltiplas racionalidades, como estratégias dialógicas (político-pedagógicas) que, em lugar da emancipação, ratificam o controle e a tutela. A esse respeito, Larrosa (1997) comenta a advertência feita por Nietzsche em seu Nascimento da Tragédia: A tese de Nietzsche parece ser que a operação socrático-platônica inaugura a época em que vivemos como a época da pedagogia, isto é, como a época que se caracteriza por um designo otimista e progressivo em relação à existência em que a regulamentação, a reforma e a transmissão do saber seriam seus instrumentos essenciais. Tal designo não é outra coisa senão a convicção de que o saber 'é capaz não só de conhecer mas inclusive de corrigir o ser' e a crença de que o conhecimento 'tem a força de uma medicina universal’ (Larrosa, 1997, p. 41).

Nesse caminho, conclui o autor, só nos restaria aceitar que não conhecemos outra forma de realidade senão aquela que está determinada pelo saber e o poder, a do código moral, que já se encontra estabelecida, como um a priori a ser desvelado. Além disso, podemos observar, em nosso presente, a manutenção e a intensificação dessa herança na concepção do ser humano presente nas psicologias. Tratase de uma concepção ligada à formulação cartesiana da cisão interior/exterior, no centro de gravidade de um 'eu', que se desdobrará tanto ao essencializar os processos cognitivos quanto ao procurar no exterior-social a saída para tal dicotomia. Na procura do "ser social”, encontramos tanto abordagens que afirmam uma subjetividade pré-existente que se (con)formariam a partir das influências dos contextos (externos) quanto aquelas que, por não admitirem a anterioridade de qualquer interior fora das determinações do contexto, definem uma subjetividade eminentemente social e cultural - que enfatizam “o papel determinante do lingüístico, do discursivo e do significado" (Domènech, Tirado e Gómez, 2001, p. 118).

\section{Os referenciais sociopolíticos da pesquisa-intervenção}

O convite a examinarmos nossa posição nas tramas de saber-poder, aproximando-nos do exercício da análise das diferenças que fazem o movimento de construção do cotidiano, exige a definição do que entendemos ser o real e a realidade. Derivam desse nosso entendimento a abordagem do concreto ou de como as coisas 
se dão à intervenção, questões eminentemente metodológicas e epistemológicas que encontramos em Marx e Engels - especialmente nas Teses sobre Feuerbach e na Ideologia Alemã. Para os autores, a partir do acompanhamento das lutas dos trabalhadores, o que se coloca como exigência frente à História é encontrar ferramentas que nos permitam escapar tanto das generalizações idealistas quanto dos relativismos permitidos pelo determinismo das circunstâncias, forjando um novo materialismo (Löwy, 2002). Assim, quando afirmamos que realizamos pesquisa e intervenção na realidade em constante movimento, do que estamos falando?

No desdobramento dessa indagação, poderíamos prosseguir destacando que o historicismo e a genealogia são modos diferenciados de apreensão do real. No primeiro, o historicismo, encontramos o plano das representações, em que se afirmam universais, sendo a realidade rebatida e codificada em certa idealização totalizadora, e os acontecimentos analisados como parte de um todo previamente organizado. Pensar, nessa perspectiva, é o exercício inato de uma faculdade, o que significa que existe uma relação dicotomizada entre a realidade, considerada externa, e o homem que a re(apresenta), (re)conhecendo o mundo por uma interiorização do visível e do enunciável (Ulpiano, 1993). O vínculo entre pensamento e realidade é de identidade e semelhança com o mundo, e a experiência se produz no domínio de um eu em dialética com o mundo; são, portanto, duas totalizações em relação: o eu e o mundo. A filosofia da representação, que sustenta a cultura ocidental-cristã e sua racionalidade, favoreceu a absorção das múltiplas experiências no uno, da diferença na identidade, do acaso na necessidade.

Já o segundo, a genealogia, está envolvida com a definição foucaultiana de real, ligada ao primado das práticas e das relações produtoras de um cotidiano que emerge na tensão de forças, movendo o presente. Nesse sentido, o que se dá é a desmistificação contida na noção de homem, enquanto unidade subjetiva e essencializada característica dos séculos XIX e XX, e da realidade como um todo orgânico a priori. A ênfase na relação, na densidade das forças, dissolve unidades como formas dadas cujo pressuposto de movimento está na harmonia e no equilíbrio sintetizado através da dialética. Nesse modo de apreensão do real, também denominado ontologia do presente, prevalece a diferença, ou o foco naquilo que difere. No cotidiano das práticas, a realidade se constitui como campo de problematização, de intensificação da vida, de experimentação do pensamento. O sentido se instaura entre representação e expressão, facultando novos modos de apreensão-produção do real. Pensar não é uma questão de vontade, é um exercício que se dá por provocação: nos encontros com o inusitado, nos afetos deslocados, na tensão entre o que já ganhou forma como homem e mundo, sujeito e objeto e o que vai se produzindo, evocando novas formas (Ulpiano, 1993). Desse modo, a representação não é uma dimensão de permanência como partes ou elementos de uma fotografia, mas um indicativo de trânsito para novas experiências.

A partir do cotidiano, das relações que criam os fatos, afirma-se a História como produção de real, e as análises como vetores que evidenciam as forças em luta.

Do contraste entre uma apreensão pela via da produção-engendramento desnaturalizadora, contingenciadora - e uma apreensão pela via da representação-reação - meramente relativizadora e próxima a um 'colapso racionalizador'. Se a primeira resulta de numa certa figura de real, numa certa totalidade sempre à beira da desfiguração, a segunda parte de uma idealidade totalizadora - O real - que deverá ser necessariamente figurada (=representada) (...) a história como tal, na
Do contraste entre uma apreensão pela via da produçãoengendramento desnaturalizadora, contingenciadora - e uma apreensão pela via da representaçãoreação meramente relativizadora e próxima a um 'colapso racionalizador'. 
qualidade de disciplina, é prática histórica de produção de real, à qual se há de indagar quanto às suas próprias condições de existência e modos de funcionamento (Rodrigues, 1993, p. 17).

A análise nos aponta a experiência enquanto positividade, afirma outras dimensões no cotidiano, aquém e além das vivências e das representações nos dualismos - é a dimensão da invenção, do plano de forças que ainda não ganhou forma, mas que nem por isso deixa de ser real. O impensado, o virtual, não se opõe ao real, mas se constitui em outro modo de ser real, é potência ( Zourabichvili, 2004).

Nessa perspectiva, pesquisar é, antes de mais nada, uma atitude que interroga os homens e os fatos em seus processos de constituição, trazendo para o campo de análise as histórias, o caráter transitório e parcial, os recortes que a investigação imprime nas práticas e a forma como produz seus próprios objetos-efeitos. Podemos afirmar que a humanidade, assim como o humano enquanto vivo, encontra-se numa trama, sendo apenas a partir dessa trama que poderemos compreendê-los. Entendemos, com Gadamer (1990), a compreensão como um ir além dos métodos ensinados ou além das faculdades adquiridas racionalmente, sendo que compreensão como atividade se desenvolve com uma atitude de rigor. A proposta do autor nos sugere a busca da positividade do pensamento, daquilo que se produz no exercício da compreensão, em lugar de investir na descoberta de como compreendemos, o que poderia nos tornar cativos dos ideais normativos e da necessidade de peritos. A potência do pensamento estaria não no apoio ou na correção da unilateralidade da Razão, mas na retomada da tensão produtiva inerente ao jogo de interações entre razão e estética: como projeto, ela "sempre atualiza em si mesma a dimensão de futuro, do por-vir” (p. 216).

Percorrer a trama num exercício de compreensão é sempre fazer escolhas, ainda que provisórias, puxar alguns fios de um presente, efetuar 'cortes de vida' e afastarnos de nossos pretensos objetos naturais. Encontrar na interioridade imperiosa do contemporâneo caminhos de escape tem sido a marca dos esforços empreendidos pelos movimentos que recusam a subordinação aos processos de colonização do pensamento no Ocidente. Tais movimentos nos autorizam a falar de uma sociedade disciplinar, mas, de forma alguma, de uma sociedade disciplinada, já que "procedimentos populares (também 'minúsculos' e cotidianos) jogam com os mecanismos da disciplina e não se conformam com ela a não ser para alterá-los” (De Certeau, 1999, p.41). Essa observação nos fala da importância de investigarmos como tais resistências à rede de vigilância são engendradas e aproximam-nos das "maneiras de fazer" que participam da ordenação sociopolítica.

Ao tratar a sociedade disciplinar, a obra foucaultiana aborda a disciplina como modo de produção, modo múltiplo de engendramento, e não como realidadetotalidade a ser representada e/ou atuada pelos agentes - sociedade disciplinada (Rodrigues, 1993, p. 17). É nesse sentido que a desnaturalização dos acontecimentos corresponde à desnaturalização de nossas práticas - dizeres e fazeres - no rastreamento de suas tramas, nas relações de força. É uma "historicidade belicosa" (Foucault, 1981, p. 7), na qual a constituição do sujeito do conhecimento não é independente daquela do sujeito ético-político. A abordagem da política como ética, a abertura para uma formação que se faça de outro modo (transformação) e a construção de um lugar diferenciado para os intelectuais-pesquisadores fizeram convergir diversas contribuições, num exercício arriscado, mas que nos incita a assumir o caráter sempre perigoso de nossas práticas. 
Novas ferramentas interventivas: experiências de transformação em território psi

Os conceitos-ferramentas institucionalistas (franceses e argentinos), os foucaultianos e os esquizoanalíticos entraram em solo carioca nos anos 70, provocando misturas e abrigando-se, diferentemente da experiência européia, no território "psi”. As primeiras ressonâncias dessas contribuições aparecem nas práticas pedagógicas, tanto em espaços de educação formal quanto naqueles caracterizados como informais ou alternativos, como em trabalhos comunitários, nos quais exercitávamos uma nova forma de pensar as práticas sociais. Confrontos e experimentações foram se constituindo em nossas práticas e marcaram diferentes estilos de atuação (Aguiar, 2003). Poderíamos dizer que, nas últimas décadas, veio se afirmando, no continente latinoamericano, uma Psicologia social como obra aberta. "Por isso, movemo-nos deliberadamente em direção a um território provisório, onde as definições, quando usadas, são somente estratégias de passagem de um sentido" (Saidon e Kamkhagi, 1991, p. 23). Na exploração dos riscos da singularização, metabolizando contribuições estrangeiras e nossas heranças, por vezes dissonantes, o desafio tem sido o de manter viva a força analisadora que tais movimentos trouxeram às práticas “psi”. Por isso, quando nos interpelam se realmente teríamos constituído uma análise institucional no Brasil (= brasileira), ou se o que fazemos é Psicologia social, respondemos investindo na constituição de práticas que possam dar consistência ao movimento que, a depender de seus agenciamentos, podem nos levar às armadilhas do mesmo ou aos escapes da subversão e da invenção.

Trataremos aqui de trazer algumas dessas referências disponibilizadas pelo institucionalismo, modo pelo qual temos nomeado os encontros pulsantes e não menos problemáticos, especialmente entre a socioanálise e a esquizoanálise ${ }^{1}$. Nos registros de sua recente história, encontramos a heterogeneidade de tendências e, dentre elas, a que temos denominado pesquisaintervenção: uma tendência nas pesquisas participativas que vem assumindo uma intervenção de caráter socioanalítico e micropolítico na experiência social (Rocha e Aguiar, 2003). Enquanto proposta de atuação (trans)formadora, ela aprofunda a ruptura com os enfoques tradicionais e amplia as bases teórico-metodológicas das pesquisas participativas. Rodrigues \& Souza (1987) evidenciam que a pesquisa-intervenção se constitui como uma crítica à política positivista de pesquisa:

A antiga proposta lewiniana vem sendo resignificada à luz do pensamento institucionalista: trata-se, agora, não de uma metodologia com justificativas epistemológicas, e sim, de um dispositivo de intervenção no qual se afirme o ato político que toda investigação constitui. Isso porque, na pesquisa-intervenção, acentua-se todo o tempo o vínculo entre a gênese teórica e a gênese social dos conceitos, que é negado implícita ou explicitamente nas versões positivistas 'tecnológicas' de pesquisa. (Rodrigues; Souza, 1987, p. 31) [grifo nosso].

Propomos tomar maio de 68 como ponto de partida para a incursão naquilo que aqui nos interessa: destacar alguns conceitosferramentas que permitam explicitar essa perspectiva. O marco histórico proposto, além de sua óbvia importância já decantada por diferentes análises, inaugura uma abordagem no trabalho social, como destaca Coimbra (1995), que radicalizam o deslocamento já posto em marcha pelo anti-institucionalismo: provoca uma inversão, transferindo a problematização das instituições de seu interior para fora, para o questionamento de suas gêneses histórico-sociais. Tal inversão e sua radicalização foram intensificadas pelos acontecimentos daqueles anos, marcados pela contestação a todas as formas de conservadorismo, expressando o que Marcuse sinalizou como "a grande recusa”.
1A proposta esquizoanalítica não se identifica com a esquizofrenia enquanto entidade clínica. Pelo contrário, a produção esquizo e a esquizofrenia estão em relação inversa. "Afirmamos que há um processo esquizo, de descodificação e de desterritorialização, que só a atividade revolucionária impede de virar produção de esquizofrenia(...) A esquizoanálise tem um único objetivo, que a máquina revolucionária, a máquina artística, a máquina analítica se tornem peças e engrenagens umas das outras" (Deleuze, 1992, $p$.

36). Para maior aproximação dos debates sobre o tema, cf. Rodrigues,1993; Barros, 1994; Rocha, 1996 e Saidon, 2002. 
"A antiga proposta lewiniana vem sendore-

significada à luz do pensamento institucionalista: trata-se, agora, não de uma metodologia com justificativas

epistemológicas, e sim, de um dispositivo de intervenção no qual se afirme o ato político que toda investigação constitui. "

Rodrigues
Esses acontecimentos são tomados por Lapassade (1977) como um laboratório histórico e condensam diferentes movimentos e contestações, no qual a experiência se realizava pela intervenção de Analisadores “acontecimento, indivíduo, prática ou dispositivo que revela, em seu próprio funcionamento, o impensado de uma estrutura social - tanto a não- conformidade com o instituído como a natureza desse mesmo instituído” (Rodrigues; Souza, 1987, p. 29). Eles funcionam como catalisadores de sentido, expõem o saber e o não saber de uma sociedade sobre si mesma e, poderíamos dizer, desnaturalizam o existente, suas condições, e, ao realizar análise, desestabilizam a cena natural de um cotidiano que nos parece estático.

A intervenção, associada à construção e/ou utilização de analisadores históricos, tira partido do deslocamento operado pelo conceito de analisador - da figura do analista para o de acontecimento - o que já é, em si, um modo de intervir nos procedimentos habituais de pesquisa que se pautam na centralização da figura do pesquisador-intérprete, ou, pela descentralização, na abertura aos participantesintérpretes. A partir daí, o que se coloca em xeque não é apenas “quem interpreta”, mas o próprio "ato de interpretar”, de fazer valer algo que "fale por todos". Se mantivermos a idéia de interpretação, que pode ser verbal ou não, é para tomá-la no sentido de movimento, de possibilidade de ruptura, sem referência a conteúdos latentes, mas à “invenção de novos focos capitalísticos [uma singularidade, uma ruptura de sentido, uma fragmentação] suscetíveis de fazer bifurcar a existência”. (Guattari, 1992, p. 30).

Aos analisadores, poderíamos acrescentar a Implicação como um outro conceito, outro modo de interpelação aos procedimentos de pesquisa e à sua decantada objetividade. A esse respeito, Lourau (1993) revela, sem evocar qualquer originalidade, que a implicação faz frente ao mito da neutralidade, referindo-se "ao conjunto das condições da pesquisa”, condições inclusive materiais, nas quais o dinheiro tem uma participação tão ‘econômica' quanto ‘libidinal'” (Lourau, 1993, p.16), daí a expressão “intelectual implicado”, que, para além de um compromisso, sugere que:

Estar implicado (realizar ou aceitar a análise de minhas próprias implicações) é, ao fim de tudo, admitir que eu sou objetivado por aquilo que pretendo objetivar: fenômenos, acontecimentos, grupos, idéias, etc. Com o saber científico, anulo o saber das mulheres, das crianças e dos loucos - o saber social, cada vez mais reprimido como culpado e inferior. O intelectual...com sua linguagem de sábio, com a manipulação ou o consumo ostensivo do discurso instituído e o jogo das interpretações múltiplas, dos 'pontos de vista' e 'níveis de análise', esconde-se atrás da cortina das mediações que se interpõem entre a realidade política e ele. O intelectual programa a separação entre teoria e política: é para comer-te melhor, minha filha... mas esquece que é o único que postula tal separação, tal desgarramento. (Lourau, 1977, p. 88-89).

Poderíamos afirmar que a implicação não é uma questão de decisão consciente de ligarse a um processo de trabalho. Ela inclui uma análise do sistema de lugares ocupados ou que se busca ocupar ou, ainda, do que lhe é designado, pelo coletivo, a ocupar, e os riscos decorrentes dos caminhos em construção. A análise das implicações com as instituições em jogo nas intervenções abre caminhos à ruptura com as barreiras entre sujeito que conhece e objeto a ser conhecido. Os deslocamentos provocados com os conceitos de analisador e de implicação nos sugerem a própria inversão do “otimismo socrático-platônico", evidenciado na fórmula conhecer para transformar. Em seu lugar, a idéia de transformar para conhecer nos religa à sabedoria 
trágica, instalando o tensionamento entre os saberes, suas exigências de aquisição, de transmissão e de respostas, e o permanente movimento de interpelação de um pensamento-acontecimento, carregado de inquietações e de incertezas. Portanto, o implicar-se do intelectual-pesquisador não se refere apenas à politização de demandas e encargos, pesquisando-interpretando as condições de sua produção social, mas exige que nos instalemos nessas condições, num engendramento sempre presente, e façamos da própria investigação-formação matéria de intervenção.

Contudo, referimo-nos a "instituições em jogo”, e essa expressão merece algumas considerações. No final da década de 60 , a análise institucional, como movimento teórico/prático (acerca dos grupos, das organizações e das instituições), definirá a Instituição como produto de uma confrontação permanente entre o instituído [aquilo que já está aí, que tende a se manter] e o instituinte [forças de subversão, de mudança] (Hess, 2000, p. 44). As ponderações de Lapassade acerca dos usos do termo "instituição" definem-na, ainda, como "forma geral que produz e reproduz as relações sociais de produção”, afastando-se dos usos mais correntes do termo que o abordam como estabelecimento/organização ou como sinônimo de técnicas de trabalho para atuar em estabelecimentos (Rodrigues; Souza, 1987, p. 33).

Os riscos dos usos maniqueístas aos quais esteve (e ainda está) exposto tal conceito foram abordados por Lourau, num curso ministrado em 1993, no Rio de Janeiro. Ao delimitar a teoria da instituição com a qual opera a análise institucional, o autor reafirma sua diferenciação em relação à concepção comumente usada, que faz corresponder instituição e organização material e jurídica. Indica o tempo social-histórico como primordial para a definição do conceito, destaca seu sentido dinâmico, no qual "o movimento, ou força de autodissolução, está sempre presente" (Lourau, 1993, p. 13) e propõe que, para pensar as separações-totalizações operadas nas e pelas formas-instituições naturalizadas, seja realizada uma análise que considere três momentos no "processo de institucionalização" que não podem ser isolados: o instituído (universalidade), o instituinte (particularidade) e a institucionalização (singularidade).

No entanto, embora trazendo um caráter dinâmico, tal abertura parece continuar exposta aos riscos de valorização (atribuindo o mal ao instituído que deve ser aniquilado pelo bem instituinte) e mais, "a tríade dialética arrisca-se, suplementarmente, a redundar numa nova filosofia (institucional) da história, na qual a contradição instituinte-instituído teria por inelutável destino desaguar... em novo instituído, fazendo de todo ato incendiário o prenúncio de uma futura sede de Corpo de Bombeiro...” (Rodrigues, 1993, p. 435).

De todo modo, queremos destacar que a socioanálise tem possibilitado o questionamento dos múltiplos sentidos cristalizados nas instituições ao afirmar seu caráter desarticulador das práticas e dos discursos instituídos, inclusive os produzidos como científicos, o que inclui a própria instituição da análise e da pesquisa. Sua proposta de produção cooperativa e autogestionária opera na perspectiva de fragilização das hierarquias burocráticas e das divisões em especialidades que fragmentam o cotidiano e isolam os profissionais. As estratégias de intervenção têm como alvo a rede de poder e o jogo de interesses que se fazem presentes no campo da investigação, colocando em análise os efeitos das práticas no cotidiano institucional, desconstruindo territórios e facultando a criação de outros modos de existência.

É nesse caminho que a restituição é redimensionada no processo grupal dos 
trabalhos de pesquisa-intervenção. A Restituição, um conceito operativo forjado no movimento institucionalista francês, se diferencia tanto da devolução, como passagem de uma interpretação verdadeira por parte de um analista a alguém ou a um grupo que, em princípio, a desconhece, quanto da confissão religiosa que procura a absolvição de possíveis culpas, no compartilhar de uma situação ou evento. A restituição "consiste em se centrar numa tarefa - a de análise coletiva da situação presente, no presente - em função das diversas implicações de cada um com e na situação" (Lourau, 1993, p. 64). Trazendo à cena o que comumente é desconsiderado ou tido como mera curiosidade nos procedimentos de pesquisa, ou o que tem seu lugar limitado à informalidade, as diferentes formas de restituição podem permitir um aumento no coeficiente de transversalidade nos grupos. O conceito de Transversalidade é utilizado por Guattari na elaboração teórica da psicoterapia institucional, durante a década de 60. Comentando os desafios da intervenção nas instituições e fazendo uso da imagem das viseiras de cavalos, o autor define a transversalidade como a superação de uma pura verticalidade (estrutura piramidal) e de uma simples horizontalidade (um certo ajeitarse na situação); constituindo-se em um terceiro vetor. A transversalidade implica a ativação da circulação, da comunicação e dos agenciamentos enquanto produção de outros modos de ser, de sentir e atuar, "ela tende a se realizar quando uma comunicação máxima se efetua entre os diferentes níveis e sobretudo nos diferentes sentidos" (Guattari, 1981, p. 96). O conceito de transversalidade foi modificado pelos socioanalistas e adquiriu um outro sentido, o de atravessamento: de funções (econômicas, ideológicas, políticas) que atravessam variadas organizações ou, em outros momentos, de instituições (casamento, escola, trabalho, Estado) que nos atravessam. Comentando essa dupla designação, Rodrigues (1993) ressalta que o conceito de transversalidade foi "proposto como contraponto ao 'centralismo democrático'” e que, “...em Guattari, o prefixo trans conduz a uma nova forma de pensar a existência, liberada dos constrangimentos disciplinares (...), mapas já estabelecidos do conhecimento" (p. 437). Embora sugerindo que "os socioanalistas tendem a alguma afirmação mais macro do socius - instâncias sociais, formas institucionais - e priorizam, nesse sentido, as reflexões sobre a reprodução", a autora alerta que tal impasse não autoriza qualquer conclusão apaziguadora no sentido de caracterizar a socioanálise que a distancie, por completo, das contribuições esquizoanalíticas.

Assim, nesse exercício de aproximações e tensionamentos entre tais contribuições, destacamos que a inversão operada pelos socioanalistas, transformar para conhecer, estabelece uma entrada para a concepção trágica, colocando em questão a verdade como guia para a busca do significado da vida e afirmando "o 'poder', isto é, a criativa abundância da vida” (Ansell-Pearson, 1997, p. 58). Poderíamos agregar as discussões acerca do Estado Inconsciente como um recurso que afasta alguns praticantes socioanalistas das divisões simplistas e reflexas das relações todoparte e dos "fantasmas de dois mundos", induzidos pelo conceito de sociedade civil e, em nosso entender, que indica outra aproximação com as contribuições esquizoanalíticas. Para Lourau, o Estado está em todo lugar, "em todas as cabeças e corpos (...) a transversalidade do Estado é total, mesmo quando não totalitário” (Lourau, 1993, p. 68-69).

O poder institucional é sempre cotidiano, dado que o legado centro político só existe, na qualidade de força permanente (presenteausente), na chamada periferia. Daí decorre a idéia de intelectual implicado: se algum Estado (= 'centro') se reproduz e há de ser por nós enfrentado, só o poderá ser mediante a investigação da presença do Estado Inconsciente nos atos falhos de nossos modos 
(= 'periféricos') de dizer, fazer e ser. (Rodrigues, 1993, p. 439).

Nesses anos, o que moveu nossas experiências foi a busca de ferramentas que favorecessem uma aproximação entre nosso campo de análise - desestabilizações acerca de nossos encargos "psi” [psicologização e despolitização] - e o campo de intervenção, marcado por aqueles encargos que nos são designados historicamente e a partir dos quais nos são dirigidas as demandas. No Rio de Janeiro, pesou nessa procura o questionamento à hegemonia dos enfoques psicanalíticos e seus efeitos na cisão entre política e subjetividade e os desdobramentos das concepções de um inconsciente-arquivo ou submetido às formas.

(...) no referencial esquizoanalítico, as formas unificantes - grupos, estabelecimentos, organizações - são consideradas simples 'pontas' (ou 'extremos') visíveis, que se 'representam' ou a que se 'reage', por mais que se as tente dialetizar/totalizar processualmente. Assim como o conceito de instituição é uma totalidade que se deve desconstruir para teorizar 'pelo meio', também os modos de ação/intervenção são mais fluidos, menos modelizados e, sobretudo, menos parolistes (=tagarelas). Criando dispositivos de enunciação, visa-se menos a instaurar situações coletivas para 'tudo dizer' - favorecedor da emergência do pretenso espontaneísmo do instituinte como trabalho do negativo - do que à abertura de mínimas consistências capazes de acolher níveis crescentes de non-sense, ou seja, de planos de expressão para o efetivo acaso dos devires. (Rodrigues, 1993, p. 436).

As elaborações esquizoanalíticas, colhidas nas obras e na atuação militante de Deleuze e Guattari, nos levaram a ponderar sobre outros aspectos nas intervenções. Um primeiro destaque poderia ser feito ao impacto produzido com a publicação de $O$ Anti-Édipo, obra que vinculava as experiências dos autores nos territórios das práticas "psi” e da filosofia e que colocava em questão tanto a hegemonia da produção psicanalítica, seus efeitos e compromissos, como trazia, para o centro da cena, as ligações entre capital e desejo. O que mais nos interessou foi a abertura, promovida pelos conceitos, para considerar, num modo de produção, as conexões diretas das relações de produção econômica e subjetiva, uma mesma economia políticodesejante. Isso tornava nossas práticas diretamente ligadas à produção de uma cultura capitalística, uma produção que conecta sistema de valor de troca - valor de uso modos de valorização do desejo, que se podiam encontrar tanto nos países periféricos quanto naqueles ditos de economia socialista.

A abordagem esquizo considera planos ou dimensões do real que não só o do concreto e da presença. Tais dimensões reconduzem a unicidade e a harmonia - habitualmente vinculadas aos sistemas organicamente estruturados - à pluralidade, à complexidade das forças produtoras da existência. A realidade não é somente o visível, e a subjetividade não se limita ao 'eu'. O que se produz é resultado do encontro de múltiplas dimensões ou de linhas de força entrelaçadas, sem que nenhuma tenha o papel de unidade transcendente - uma textura ontológica que, por composições, fabrica novas figuras, estados inéditos à nossa consistência subjetiva atual (Rolnik, 2002). Estamos, desse modo, trabalhando na perspectiva da imanência, na qual relações de forças, engendramentos e produções (plano micropolítico/virtualidades) não se encontram em relação de oposição com as formas e as organizações de poder (plano macropolítico/simbólico), mas num regime de coextensão - o desejo é potência e é coextensivo ao social. O Inconsciente é aqui abordado como pura produção.

A realidade criada na perspectiva da imanência recusa um ponto de partida, um sujeito ou 
uma idéia deflagradores dos acontecimentos, passando da noção de possível, entendida enquanto material disponível à criação ou à tomada de decisões, para um possível enquanto engendramento, como invenção (Gallo, 2003). Desse modo, na realização de um "ser" na dimensão da atualidade, algo continua, permanece em vias de se atualizar, de ganhar corpo. Dessa perspectiva, a transformação do existente (nos grupos, nas organizações, nos indivíduos) não se limita à criação de condições ou meios adequados à realização de um potencial, mas refere-se a uma micropolítica que implica o intensivo, os processos de constituição de realidades, que abre o atual à pluralidade do socius e qualifica a trans-formação enquanto criação de possíveis. A dimensão micropolítica revela ser mais que uma dimensão na escala espacial (a do lugar) ou que uma temporalidade (a do cotidiano), abrindo a história à experiência que se espreita no cotidiano.

A questão micropolítica - ou seja, a questão de uma analítica das formações do desejo no campo social - diz respeito ao modo como se cruza o nível das diferenças sociais mais amplas (que chamei de 'molar'), com aquele que chamei de 'molecular'. Entre esses dois níveis, não há uma oposição distintiva que dependa de um princípio lógico de contradição. Parece difícil, mas é preciso simplesmente mudar a lógica. $\mathrm{Na}$ física quântica, por exemplo, foi necessário que um dia os físicos admitissem que a matéria é corpuscular e ondulatória, ao mesmo tempo. Da mesma forma, as lutas sociais são, ao mesmo tempo, molares e moleculares... (Guattari; Rolnik, 1986, p. 127).

A noção de movimento, que ganha consistência entre a Macro e a Micropolítica, não se faz pela negação, ou seja, pela busca da síntese como na dialética hegeliana, mas pela positividade vinculada à "vontade de potência”" constituída nas experiências que criam sentidos na história dos homens. Em Nietzsche, ...a relação essencial de uma força com a outra nunca é concebida como um elemento negativo na essência (...) O negativo nunca está presente na essência como aquilo de que a força tira sua atividade, pelo contrário, ele resulta dessa atividade, da existência de uma força ativa e da afirmação de sua diferença. (Deleuze, 1976, p. 7).

No desenrolar de um movimento, nosso pensamento e nossas ações não têm início em uma contraposição, mas emergem em um conjunto de forças entre as quais existem oposições: um movimento não surge necessariamente da crítica de um outro, o que não impede que possamos compará-los nas suas incompatibilidades.

A experiência tem início com um corte no caos que instaura um plano de composição, e este constitui as condições da própria experiência em que pensar o que há é tomar consciência, é dar corpo, é atualizar. Para Lévy (1996), o virtual é a potência do pensamento da experiência, “é como o complexo problemático, o nó de tendências ou de forças que acompanha uma situação, um acontecimento...” (p. 16), Nesse sentido, “o virtual não se opõe ao real, mas ao atual: virtualidade e atualidade são apenas duas maneiras de ser diferente.” (p.15). A virtualização é, então, o processo de transformação de um modo de ser num outro, e não cabe investir na busca do fundamento último das coisas e dos acontecimentos, na medida em que são constituídos por forças e tensões historicamente situadas e, portanto, parciais, mutáveis; as transformações não são alavancadas por evolução e retificação, mas pelo diferencial de forças que intensificam a potência. Segundo Zourabichvili (2004), a dialética se dá no plano das formas atualização do acontecimento, superfície dos corpos -, enquanto a multiplicidade se faz nos encontros, na imanência, no plano das forças. Como evidencia o autor, a multiplicidade, na obra deleuzeana, é um conceito que afirma um duplo deslocamento: 
... de um lado, a oposição do um e do múltiplo cessa de ser pertinente; de outro, o problema torna-se o da distinção de dois tipos de multiplicidade (atual-extensiva, que se divide em partes exteriores umas às outras, como a matéria ou a extensão, e virtual-intensiva, que não se divide senão em dimensões englobadas umas nas outras, como a memória ou a duração). (Zourabichvili, 2004, p. 70).

Assim, retomando Nietzsche, Deleuze (1976) substitui o elemento negativo do movimento contraditório pelo elemento da diferença, do múltiplo como movimento de afirmação. Foucault (1999) também sustenta que a dialética reafirma o sujeito universal na História, viabilizando uma ordenação, uma verdade reconciliada:

No fundo, a dialética codifica a luta, a guerra e os enfrentamentos dentro de uma lógica, ou pretensa lógica, da contradição; ela os retoma no duplo processo da totalização e da atualização de uma racionalidade que é, a um só tempo, final, mas fundamental, e, em todo o caso, irreversível. (Foucault, 1999, p. 69).

Segundo o autor, a dialética, na ordem filosófica e na política, é pacificação do que se constitui como o discurso inevitável da guerra fundamental. Buscar a filosofia do silêncio em Marx que evidencia um Marx Trágico (Escobar, 1993), ou extrair dele o Filósofo da Potência (Escobar, 1996) é resgatar o que, em Nietzsche e em Deleuze, afirma o movimento na multiplicidade e instaura a lógica do $e$ entre as coisas, não para oscilar de uma a outra, nem para constituir a média, mas para ser atravessado, pois é no entre que a produção ganha consistência.

\section{Práticas de pesquisa: outros suportes, novos desafios}

A pesquisa-intervenção, por sua atitude crítica (inventiva) e implicativa (desnaturalizadora), se afasta de posturas e posições reativas (de negação e julgamento) e amplia as condições de um trabalho compartilhado. Em nosso presente, as práticas emancipatórias que se sustentam no conceito de ideologia, vinculando-se à visão de uma sociedade bipolarizada, cujo movimento se faz pela contradição entre as classes nos seus valores, interesses e necessidades, merecem ser abordadas com cautela. O que está em questão não é deixar de considerar a possibilidade de um recorte do social referido às classes, mas perceber que outras clivagens podem estar em jogo, pois as formas de inserção na vida social são múltiplas e, além disso, outros vetores podem estar movendo o cotidiano do coletivo com mais intensidade (Guattari; Rolnik, 1986). Nesse sentido, não se trata de substituir a análise de classes por qualquer outra estabelecida a priori, nem por análises que cotejem os movimentos populares e os grupos como grupos-em-si ou grupos-para-si, mas considerar os grupos como dispositivos de afirmação de outros modos de subjetivação, realidades abordadas micro e macropoliticamente.

É desse modo que iremos procurar marcar na experiência, naquilo que acontece, a experiência como acontecimento. Foucault assim o diz:

Acontecimento não é uma decisão, um tratado, um reino, ou uma batalha, mas uma relação de forças que se inverte, um poder confiscado, um vocabulário retomado e voltado contra seus utilizadores, uma dominação que se enfraquece, se distende, se envenena e uma outra que faz sua entrada, mascarada. (Foucault, 1981, p.28).

Para o autor, inspirado na abordagem histórica proposta por Nietzsche, inverte-se a relação dada como natural entre a irrupção do acontecimento e a continuidade ideal da História. É que a tradição histórica constituiu um mundo simplificado de essências e finalidades, um mundo sem acontecimentos. Nesse sentido, contar histórias através de analisadores é buscar que "se instaurem novos regimes de verdade, baixos começos que 
movem montanhas, lutas que se opõem à mitificação de pequenos segredinhos, banalidades da ação que preservam (ou ferem) grandes dominações”. (Rodrigues, 1993, p. 444).

A percepção da dimensão histórica da vida social é, sem dúvida, um dos desafios à transformação; é ela que faz possível a crítica à naturalização das instituições, das funções que lhe são atribuídas e dos papéis a serem desempenhados. A dimensão histórica evoca as instituições, as funções e os papéis enquanto invenções dos homens e é, portanto, fruto do encontro e do confronto de interesses. Mas a consideração do poder em termos de interesse parece não dar conta dos impasses vividos nas organizações dos movimentos populares urbanos, já que as modalidades de resistência também implicam toda uma micropolítica do desejo. A esse respeito, Deleuze chamou a atenção para os impasses no desempenho de partidos e sindicatos que podem fazer investimentos revolucionários na defesa do interesse de classe (macropolítica) e investimentos reacionários ao nível do desejo (micropolítica) (Foucault, 1981, p. 76). O que a abordagem micropolítica nos sugere é a problematização dessa relação interesse-desejo-poder a partir do rastreamento de lutas específicas, de um exercício de acoplamento das teorias e memórias locais. Entendemos que é daí, desses nossos lugares, que podemos produzir outras análises, movimentos e demandas e perguntarmos: o que queremos transformar?

Katia Faria de Aguiar

Prof $^{a}$ adjunta e pesquisadora em Psicologia social do Departamento de Psicologia da Universidade Federal Fluminense. Mestre em Educação pela UFF e Doutora em Psicologia social pela PUC/SP

\section{Marisa Lopes da Rocha}

Prof $^{a}$ adjunta e Pesquisadora em Educação do Departamento de Psicologia social e institucional da Universidade do Estado do Rio de Janeiro. Mestre em Filosofia da Educação pelo IESAE/FGV e Doutora em Psicologia pela PUC/SP

Rua Joaquim Pinheiro, 55/Bl I/ap. 501. Freguesia - Rio de Janeiro CEP 22.743-660 tel (21) 3327.8586

E-mail: katiafaguiar@uol.com.br,marisalrocha@uol.com.br, marisalrocha@uol.com.br 
AGUIAR, K. F. Ligações perigosas e alianças insurgentes. Subjetividades e movimentos urbanos. Tese (doutorado em Psicologia social) - Pontifícia Universidade Católica de São Paulo, São Paulo, 2003.

ANSELL-PEARSON, K. Nietzsche como pensador político - uma introdução. Rio de Janeiro: Jorge Zahar, 1997.

BARROS, R. D. B. Grupos: a afirmação de um simulacro. Tese (doutorado em Psicologia Clínica) - Pontifícia Universidade Católica de São Paulo, São Paulo, 1994.

COIMBRA, C.M. B. Os caminhos de Lapassade e da Análise Institucional: uma empresa possível. Revista do Departamento de Psicologia da UFF, 7 (1), Niterói, p. 52-80, 1995.

De CERTEAU, M. A invenção do cotidiano. 5 a ed. Petrópolis, RJ: Vozes, 1999

DELEUZE, G. Nietzsche e a filosofia. Rio de Janeiro: Editora Rio, 1976.

Conversações. Rio de Janeiro: 34, 1992.

DOMÈNECH, M., TIRADO, F., \& GÓMEZ, L. A Dobra: Psicologia e subjetivação. In: SILVA, T.T. (Org.). Nunca fomos humanos - nos rastros do sujeito. Belo Horizonte:Autêntica, 2001. p. 137-204.

ESCOBAR, C. H. Marx Trágico. Rio de Janeiro: Taurus, 1993.

ESCOBAR, C. H. Marx: Filósofo da potência. Rio de Janeiro: Taurus, 1996.

FOUCAULT, M. Microfísica do poder. $2^{\mathrm{a}}$ ed. Rio de Janeiro: Graal, 1981.

Fontes, 1999.

Em defesa da sociedade. São Paulo: Martins

GADAMER, H. G. Filosofias. Entrevistas do Le Monde. São Paulo: Ática, 1990.

GALLO, S. Deleuze \& a Educação. Belo Horizonte: Autêntica, 2003.

GUATTARI, F. Revolução molecular. Pulsações políticas do desejo $2^{\mathrm{a}}$ ed. São Paulo: Brasiliense, 1981.

GUATTARI, F. \& ROLNIK, S. Micropolítica. Cartografias do desejo Petrópolis: Vozes, 1986.

GUATTARI, F. Caosmose. Um novo paradigma estético. Rio de Janeiro: Ed. 34, 1992.

HESS, R. L'institutionnalisation In: Pratiques de analyses de formation. Paris: Université de Paris VIII, 2000, p. 43-52.

LAPASSADE, G. El análisis institucional. Madrid: Campo Abierto Ediciones, 1977.
LARROSA, J. Filosofia e modernidade: racionalidade, imaginação e ética. Educação e Realidade, Porto Alegre, 22 (1), p. 33-55, 1997.

LÉVY, P. O que é o virtual? São Paulo: Editora 34, 1996.

LOURAU, R. El Análisis Institucional. Madrid: Campo Abierto, 1977.

Análise Institucional e Práticas de Pesquisa. In RODRIGUES, H. B. C. (Org.). René Lourau na UERJ. Rio de Janeiro: UERJ, 1993.

LÖWY, M. A. Teoria da Revolução no Jovem Marx. Petrópolis: Vozes, 2002.

OLIVEIRA, M. D. \& OLIVEIRA, R. D. Pesquisa social e ação educativa: conhecendo a realidade para poder transformá-la. In: C. R. BRANDÃO (Org.). Pesquisa participante. São Paulo: Brasiliens, 1983. p. 17-33.

RIZZINI, I., CASTRO, M. R. \& SARTOR, C. D. Pesquisando... Guia de metodologias da pesquisa para programas sociais. Rio de Janeiro: Universidade Santa Ursula, 1999.

ROCHA, M. L. Do tédio à cronogênese: uma abordagem éticoestético-política da prática escolar. Tese (doutorado em Psicologia clínica) - Pontifícia Universidade Católica de São Paulo, São Paulo, 1996.

ROCHA, M. \& AGUIAR, F. Pesquisa-intervenção e a produção de novas análises. Psicologia: Ciência e Profissão, 4, p. 64-73, 2003.

RODRIGUES, H. B. C. \& SOUZA,V. L. B. A análise institucional e a profissionalização do psicólogo. In: O. SAIDON \& V. R. KAMKHAG (Orgs.). Análise institucional no Brasil. Rio de Janeiro: Espaço e Tempo, 1987. p. 17-35.

RODRIGUES, H. B. C. As subjetividades em revolta. Institucionalismo francês e novas análises. Dissertação (mestrado em Saúde Coletiva) - Universidade do Estado do Rio de Janeiro, Rio de Janeiro, 1993.

ROLNIK, S. (2002). Despachos no museu: sabe-se lá o que vai acontecer.... In: RAGO, M.; ORLANDI, L. B. L.; VEIGA-NETO, A.(Orgs.). Imagens de Foucault e de Deleuze. Rio de Janeiro: DP\&A, 2002. p. 309-323.

SADER, E. Quando Novos personagens entram em cena. São Paulo: Paz e Terra, 1988.

SAIDON, O. \& KAMKHAGI, V. R. (Orgs.). Análise institucional no Brasil. 2aed. Rio de Janeiro: Espaço e Tempo, 1991.

SAIDON, O. Clínica y sociedad. Esquizoanalisis. Buenos Aires: Lumem, 2002.

ULPIANO, C. A estética deleuziana. Oficina Três Rios, PUC/SP (22 e $24 / 11 / 1993)$

ZOURABICHVILI, F. O vocabulário de Deleuze. Rio de Janeiro: Relume-Dumará, 2004.
Referências 